Revue d'histoire de l'Amérique française

6. REVUE D.HISTOIRE DE L'AMÉRIQUE FRANÇAISE

\title{
Rome et la codification des lois du Québec en 1865
}

Volume 6, numéro 1, juin 1952

URI : https://id.erudit.org/iderudit/301507ar

DOI : https://doi.org/10.7202/301507ar

Aller au sommaire du numéro

Éditeur(s)

Institut d'histoire de l'Amérique française

ISSN

0035-2357 (imprimé)

1492-1383 (numérique)

Découvrir la revue

Citer ce document

(1952). Rome et la codification des lois du Québec en 1865. Revue d'histoire de l'Amérique française, 6(1), 118-123. https://doi.org/10.7202/301507ar d'utilisation que vous pouvez consulter en ligne.

https://apropos.erudit.org/fr/usagers/politique-dutilisation/ 
ROME ET LA CODIFICATION DES LOIS DU QUÉBEC EN 1865

I - Mgr Bourget écrit au cardinal Barnabo, préfet de la Sacrée Congrégation de la Propagande, pour signaler à son attention les erreurs qu'il trouve dans cette codification:

Eminentissime Seigneur,

Rome, le 28 février 1865

Comme votre Eminence étend, au nom du Souverain Pontife, sa sollicitude sur notre pays, je crois devoir l'informer qu'il s'y passe maintenant quelque chose qui pourrait compromettre gravement les intérêts de la Religion. Voici ce dont il s'agit:

Notre Législature, croyant que nos lois avaient besoin d'être rédigées sous une nouvelle forme, en ordonna, en 1857, la condification, et le gouvernement confia ce soin à quelques juges. 
Le travail étant fini, il est soumis, comme il devait l'être, à la discussion des chambres, qui ont à s'en occuper, dans leur présente session. Or, voici ce que j'ai à observer à Votre Eminence là-dessus.

1. Cette codification, calquée sur le Code-Napoléon, ne reconnaît l'assistance d'aucune religion en Bas-Canada, quoique la Religion eatholique y ait été reconnue même par le Gouvernement Britannique. Elle ne prononce pas une seule fois le nom de Dieu: ce qui en ferait un Code athée, s'il était adopté tel quel par la Législature.

2. Dans une première rédaction, la codification n'avait pas placé, parmi les empêchements de mariage, 10 les Ordres sacrés ; 2o les rapts; $3 o$ la séduction; 40 le meurtre; 50 l'adultère; 60 l'alliance spirituelle; 7 o l'honnêteté publique; 80 la clandestinité; qui, dans notre code actuel se trouvent dans la liste des empêchements.

3. Ces empêchements se trouvent rétablis, dans un nouveau cahier publié par les codificateurs, mais d'une manière si obscure qu'il sera bien difficile de les maintenir en vigueur contre les chicanes d'une telle loi. On en doit dire autant de l'empêchement produit par la profession religieuse.

4. Comme elle ne fait aucune distinction entre les empêchements dirimants et les empêchements empêchants, cette codification ne peut que produire des résultats déplorables.

5. Elle dófend le mariage des mineurs, sans le consentement des parents, mais elle ne dit pas sous quelle peine; et il est à croire qu'elle le frappe de nullité.

6. Elle fait, du fonctionnaire qui a droit de célébrer le mariage, un officier purement civil, si bien que le mariage de deux catholiques, contracté devant n'importe lequel de ces officiers civils, sera légalement valide.

7. Dans cette codification, la puissance ecclésiastique est subordonnée à la puissance civile.

8. L'officier civil qui reçoit le consentement des parties peut refuser de les marier, s'il trouve qu'elles sont liées par des empêchements, et personne ne peut le contraindre à procéder à leur mariage; mais si néanmoins il le faisait, il ne serait pas répréhensible, comme gens de la loi, et son acte serait légalement valide, si une telle disposition de la Codification était sanctionnée par la Législature.

9. La codification statue que le mariage doit être fait publique, mais elle ne dit pas en face d'Église. D'où l'on conclut que le mariage est légalement valide, dès qu'il a de la publicité, quoiqu'il n'ait pas été fait coram parocho, et par une conséquence nécessaire, la codification n'admet pas la clandestinité, comme empêchement dirimant. Cependant, dans notre ancien code, les lois ecclésiastiques, à peu de chose près, se trouvaient en harmonie avec les lois civiles.

Telles sont, Eminentissime Seigneur, les principales erreurs de la dite codification, que je crois devoir signaler à votre sérieuse attention, pour que vous puissiez, dans votre sagesse, vous puissiez y apporter un prompt et souverain remède. 
J'ai l'honneur d'être sincèrement, Eminentissime Seigneur, avec un profond respect, le très humble et très dévoué serviteur. (Signé) Ig. Ev. de Montréal.

- N.B. Cette lettre, toute autographe, se trouve aux Archives de la S.C. Propag., dans la série Scritture riferite nei Congressi: America Settentrionale, vol. 8 (1862-1865), fol. 1308-1309v. En marge du folio 1308, se trouve l'indication du jour où elle a été référée à l'audience du Saint-Père: "Riferita al Santo Padre nell'Udienza delli 5 Marzo 1865". Sur l'endos de la lettre, fol. $1309 \mathrm{v}$, se trouve également une note indiquant que le [ 27 ] mars 1865 on a écrit, en conséquence, à Mgr de Tloa (si scrive al Vescovo di Tloa), c'est-àdire à Mgr C.F. Baillargeon, administrateur de l'archidiocèse de Québec.

II - Mgr Baillargeon, administrateur du l'archidiocèse de Québec, répond au cardinal Barnabô qui, de la part du Saint-Père, lui avait demandé d'intervenir auprès des codificateurs et des ministres catholiques pour leur exprimer l'anxiété du Souverain Pontife au sujet de cette codification et les inciter à faire en sorte qu'on ne sanctionne pas des lois contraires à l'honneur de la religion et aux droits de l'Église.

Québec, le 3 juin 1865

Eminentissime et Reverendissime Domine,

Litteris suis, die 27 Martii nuper elapsi datis, Eminentia tua scripsit mihi quos sequitur:

"Delatum est SSmo D.N. non parum timeri posse ne opus reformationis civilis Codicis susceptum in inferiore regione Canadensi aliquod prejudicium rei christianae sit allaturum. Quare Sanctitas Sua tuae sollicitudini committit ut catholicis viris quibus inter caeteros cura praedictae reformationis conficienda fuit demandata, necnon ministris catholicis ejusdem regionis significes suam hac super re anxietatem, eosque excites ut efficaciter studeant ne contingat leges sanciri quae divinae religionis honori, et ecclesiasticis juribus adversantur."

Sanctitatis suae sapientissimam et admodum venerandam admonitionem gratissimo animo suscipient, reverenter respondeo quod opus susceptum, et jam confectum, circa jus civile hujus provinciae non fuit proprie reformationis, sed potius redactionis novae, seu (ut vocatum est apud nos) codificationis. Si quid reformationis in eo reperitur, illud circa formam magis quam circa substantiam versatur.

Viri tres eminentes, inter quos duo catholici erant, quibus hoc opus commissum fuit, mandatum habebant non novas leges condendi, sed antiquas, inordinate digestas, ac in varias codicibus dispersas colligendi, atque ordine, stilo, methodoque meliori in unum codicem redigendi. Quod quidem, juxta communem sententiam prudentium ac piorum virorum, fideliter probeque fecerunt ; quidque in contrarium dixerint aut scripserunt quidam ex nostris junioribus legis peritos. Catholici viri, sincero animo religioni et 
Petri Cathedrae addicti, strenue pro juribus ecclesiae contra collaboratorem suum acatholicum pugnaverunt, atque illa, quantum potuerunt servaverunt. A me rogati libenter correxerunt quasdam additiones, seu potius omissiones, dictis juribus ecclesiae contrarias, quae incaute et praeter intentionem irrepserant in opere.

Unde meo judicio non est timendum ne novus codex civilis hujus provinciae aliquod prejudicium rei christianae afferat. Eaedem enim ac antea sunt leges nostrae, licet sub diversa forma, ac novo ordine, in hoc libro expressae.

Equidem iste codex non vacat erroribus. Sane nonnullae in eo reperiuntur leges non concordantes cum jure ecclesiastico, maxime circa matrimonium. At hujusmodi leges jam obtinebant apud nos, tanquam partes juris antiqui Galliae, quod semper viguit, ac adhuc viget in hac provincia. Porro, ut jam dixi, viri illi nostri, quibus cura conficiendi praefatum codicem demandata fuit, leges nostras colligere et ordinare jussi erant, non autem easdem mutare aut emendare. Accedit tandem illud quod hujusmodi emendatio valde optanda quidem est; perdifficile autem, ne dicam impossibile fuisset eam impetrare a gubernio nostro, in quo pars acatholica dominatur.

De cetero autem, pro futuro diligenter attendam voci Sanctitatis Suae, mandatumque ejus sollicitudini meae committit [ commissum ] ut legislatoribus necnon et ministris catholicis hujus regionis significem Suam hac super re anxietatem, eosque quantum in me erit, excitem "ut efficaciter studeant ne contingat leges sanciri, quae divinae religionis honori et ecclesiasticis juribus adversantur," fideliter servabo.

Eminentiae tuae humillimus et devotissimus

(signê) C.F. Epus Tloan.

Ex archiep. aedib. Quebecensis, die 3 Junii 1865.

- Arch. S.C. Prop., Scritture riferite nei Congressi: America Settentrionalis, vol. 8 (1862-1865), fol. 1378-1379v. Au fol. 1379v, on a noté que la réponse à cette lettre a été donnée au mois d'août 1865. D'autre part, en marge d'une lettre française de Mgr Baillargeon accompagnant sa lettre latine, le Secrétaire de la Propagande a noté (fol. 1377), que celle-ci a été référée au SaintPère à l'audience du 2 juillet 1865 .

(Traduction française de la précédente lettre).

Eminentissime et Révérendissime Seigneur,

Québec, le 3 juin 1865.

Dans votre lettre en date du 27 mars dernier, votre Fminence m'écrivait ce qui suit:

"Il a été porté à la connaissance du Très Saint-Père que l'on n'est pas sans appréhender sérieusement que ne porte préjudice aux intérêts de 
l'Église, ce travail de refonte du code civil entrepris dans la province $d u$ bas Canada. C'est pourquoi Sa Sainteté confie à votre sollicitude le soin de faire savoir ses craintes à ce sujet à ceux d'entre les catholiques à qui a été confie ce travail de codification, ainsi qu'aux ministres catholiques du bas Canada, et d'insister vivement auprès d'eux pour qu'ils s'appliquent efficacement à ce qu'il n'y ait point de lois formulées contre l'honneur de la religion divine ou contre les droits ecclésiastiques."

En vous assurant d'abord la profonde gratitude avec laquelle sera accueilli le très sage et très respectable avertissement de Sa Sainteté, je me permets d'ajouter respectueusement que l'œuvre entreprise, et maintenant terminée, dans le domaine du droit civil de la province, n'a pas été une refonte proprement dite, mais plutôt une rédaction nouvelle ou encore, selon le langage courant, une codification. S'il y a refonte dans ce travail, la refonte porte beaucoup plus sur la forme que sur le fond.

Trois hommes éminents, dont deux catholiques, s'étaient vu confier ce travail et ils avaient à cette fin le mandat non pas de faire de nouvelles lois mais de colliger les anciennes lois mal ordonnées et dispersées ici et là dans des codes divers, pour les intégrer avec ordre et méthode dans un code unique, en les formulant dans une meilleur langue juridique. Et ce travail, ils l'ont fait soigneusement et équitablement, selon l'appréciation générale d'hommes prudents et consciencieux, peu importe ce qui a été dit ou écrit en sens contraire par quelques-uns de nos jeunes juristes. Ces hommes catholiques, animés d'un dévouement sincère à l'endroit de la religion comme à l'égard de la Chaire de Pierre, ont courageusement défendu, en présence de leur collaborateur non catholique, les droits de l'Église et, partant, ont servi Celle-ci dans la mesure du possible. A ma demande, ils ont volontiers corrigé quelques additions ou plutôt réparé des omissions, qui étaient contraires aux droits de l'Église et qui s'étaient glissées accidentellement dans le travail à l'insu des codificateurs.

$\Pi$ s'ensuit qu'il n'y a pas à craindre, à mon avis, que le nouveau code civil de cette province porte quelque préjudice aux intérêts chrétiens en jeu. Ce sont en effet les mêmes lois que nous avions qui se trouvent maintenant formulées dans ce code, sous une forme différente cependant et selon une nouvelle disposition.

Ce code certes n'est pas sans imperfections. On y retrouve en effet quelques lois qui ne concordent pas avec le droit ecclésiastique, surtout en ce qui concerne le mariage. Mais ces lois discordantes existaient déjà chez-nous, comme partie intégrante de l'ancien droit français, droit qui existait alors et qui est encore en vigueur dans la province. De plus, comme je l'ai dit plus haut, ces hommes de chez nous qui s'étaient vus confier le soin de rédiger ce code, avaient reçu l'ordre de grouper nos lois et de les disposer dans un tout logique, mais non pas de les changer ou de les amender. Enffin il est fortement à désirer que l'on obtienne un changement dans ce domaine, mais c'est là une chose très difficile, pour ne pas dire 
qu'il aurait été impossible de l'obtenir de notre parlement dont la majorité est non catholique.

Quant au reste j'apporterai une attention diligente aux directives de Sa Sainteté pour l'avenir et je remplirai fidèlement la charge qu'il a confiée à ma sollicitude de faire savoir ses craintes à ce sujet aux législateurs ainsi qu'aux ministres catholiques de la région et d'insister vivement auprès d'eux, dans la mesure du possible, pour "qu'ils s'appliquent efficacement à ce qu'il n'y ait point de lois formulées contre l'honneur de la religion divine ou contre les droits ecclésiastiques."

De votre Eminence le très humble et très dévoué serviteur.

De notre palais archiépiscopal de Québec, le 3 juin 1865.

C.F. Ev. de Tloa.

\section{IV}

\section{RÉPONSE A UN CORRESPONDANT}

Un correspondant nous demande: "Quelle part tenaient les Canadiens français, dans le mouvement industriel ou commercial à Montréal, vers l'époque de 1850 ?'" Nous publions ici cet extrait d'une brochure des Archives du Canada No 2584, v. 1. Le document n'est donc pas inédit. Mais comme il n'est pas à la portée de tout le monde, nous publions ici cette pièce qui peut avoir son importance dans l'histoire économique du Canada de ce temps-là. Nous l'extrayons de: Montreal in 1856. A Sketch prepared for the Celebration of the Opening of the Grand Trunk Railway of Canada, by a Sub-Committee of the Celebration Committee. (Montreal, Printed by John Lovell, 1856). 